\title{
5-DOF Controlled Self-Bearing Motor
}

\author{
Tatsuya ISHIKAWA ${ }^{* *}$, Ken-ichi MATSUDA ${ }^{* *}$, Ryou KONDO** \\ and Toru MASUZAWA ** \\ **Department of Mechanical Enginnering, Ibaraki University, \\ 4-12-1 Nakanarusawa-cho, Hitachi City, Ibaraki, 316-8511, Japan \\ E-mail: kmatsuda@mx.ibaraki.ac.jp
}

\begin{abstract}
A novel 5-DOF actively controlled self-bearing motor that combines the functions of a motor, two radial AMBs, and an axial AMB has been developed to achieve smaller size and higher performance simultaneously. In this paper, magnetic suspension performance of the 5-DOF controlled self-bearing motor is reported. First, radial control performance of the developed self-bearing motor is evaluated by the radial experimental setup. Next, tilt control performance and 5-DOF active control performance are evaluated by the 5-DOF experimental setup. Finally, the frequency response in the 5-DOF is measured with the contact-free levitation. The 5-DOF controlled self-bearing motor produced sufficient radial force and tilt control torque to overcome the radial negative stiffness and to stabilize the rotor. The sufficient frequency bandwidth was observed in the frequency response and the self-bearing motor successfully suppressed vibration at the resonant frequencies.
\end{abstract}

Key words: Self-Bearing Motor, 5-DOF Active Control, Active Magnetic Bearing

\section{Introduction}

Active magnetic bearings (AMBs) have been used to suspend rotors without mechanical contact. Contact-free levitation with the AMBs has many advantages such as elimination of lubrication, high rotational speed, clean operation, and low acoustic noise. Smaller-sized AMB systems are required for applications in various industrial fields. Self-bearing motors, which are combined the functions of a motor and an AMB, have been developed to minimize the magnetic bearing systems [1]. The authors have developed a radial self-bearing motor for a magnetically levitated centrifugal blood pump [2], [3] as a application of the self-bearing motor. This blood pump has the potential to be a long-life artificial heart using small and durable self-bearing motor. In the self-bearing motor, two degrees of freedom (radial directions: $x, y$ ) are controlled actively. The remaining three degrees of freedom are stabilized passively with magnetic reluctance forces. The passive stabilization allows AMB's or the appliances to be smaller, have lower power consumption, have simpler structure, and reduce the number of sensors. However, the low stiffness and the low damping characteristics of the passive stability sometimes result in instability of the system.

In this study, a 5-DOF self-bearing motor, which controls five degrees of freedom (radial directions: $x, y$, axial direction: $z$, rotation around $x$ and $y: \theta_{x}, \theta_{y}$ ) actively, has been developed. Functions of a motor, two radial AMBs, and an axial AMB are effectively combined in the self-bearing motor to miniaturize the system with higher performance.

The authors have already presented the theory of the force and torque generation of the 
5-DOF self-bearing motor [4], the numerical results of the self-bearing motor [5], and the experimental results of motor and axial control performance [6]. In this paper, the radial control performance, the tilt control performance, and the 5-DOF active control performance of the 5-DOF self-bearing motor are reported.

\section{Structure of the 5-DOF self-bearing motor}

Figure 1 shows the structure of the 5-DOF self-bearing motor. The stator has twelve salient poles which has overhang structure on the edge of the rotor circumference. The salient poles are composed of two overhanging pole sections over the rotor edge and a central pole section. The four types of coils are wound around each of the salient poles. Coils for tilt control and axial position control are wound around the overhanging pole section. Coils for radial position control and motor are wound around the base part of the salient poles.

Figure 2 shows a schematic diagram and a photograph of the suspended rotor. Four permanent magnets for regulation of the radial position of the rotor are mounted on the circumferential surface of the rotor. Other two sets of four permanent magnets are respectively set on both the front and back side of the rotor for regulation of the axial position and the tilt movement of the rotor. The thickness of the permanent magnets is 1 $\mathrm{mm}$. The magnetic polarities for each permanent magnet in the same angular position are identical. The edges of the permanent magnets are tapered to generate a sinusoidal-like waveform of the flux density. The diameter of the rotor made of laminated silicon steel is $60 \mathrm{~mm}$.

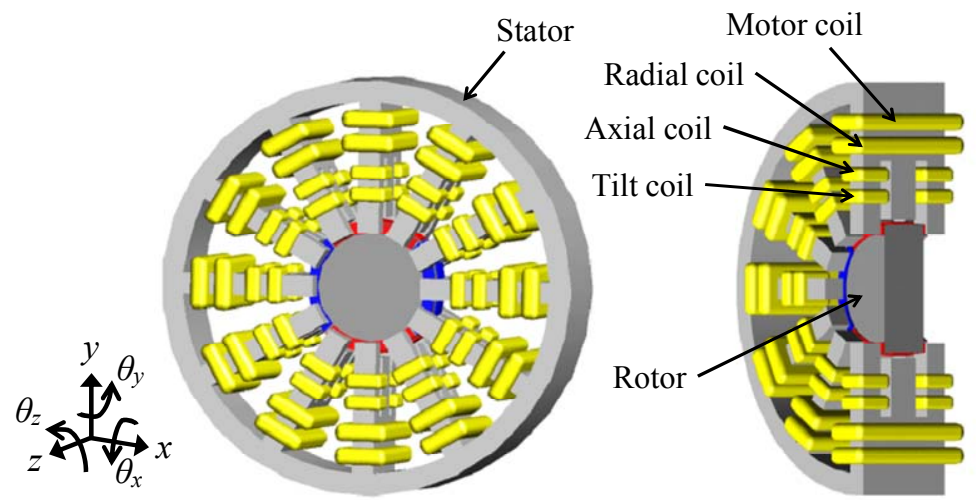

Fig. 1 Structure of 5-DOF self-bearing motor
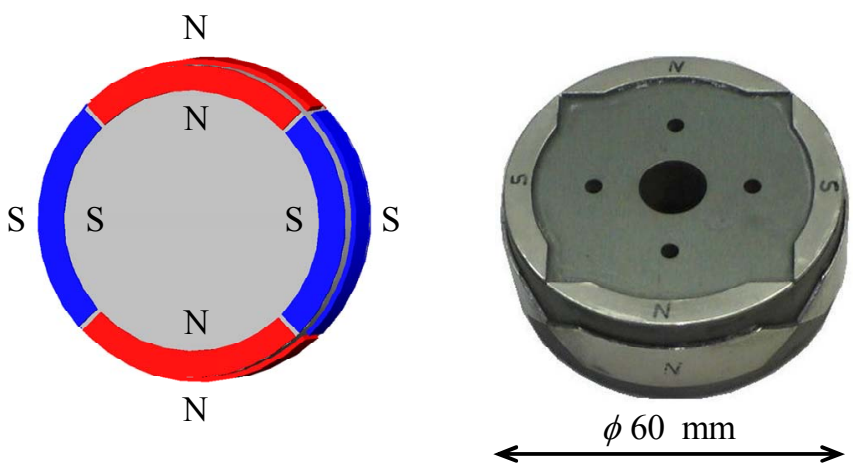

Fig. 2 Schematic diagram and photograph of rotor 
Figure 3 shows the dimensions of the 5-DOF self-bearing motor. Table 1 summarizes the parameters for the 5-DOF self-bearing motor. Figure 4 shows a photograph of a divided stator made of laminated silicon steel with excitation coils. The stator is designed to be divided into twelve parts. The diameter of the coil wire is $0.5 \mathrm{~mm}$. The weight of the rotor is $890 \mathrm{~g}$. The moment of inertia of the rotor is $I_{x x}=I_{y y}=1.725 \times 10^{-3} \mathrm{~kg} \cdot \mathrm{m}^{2}$.
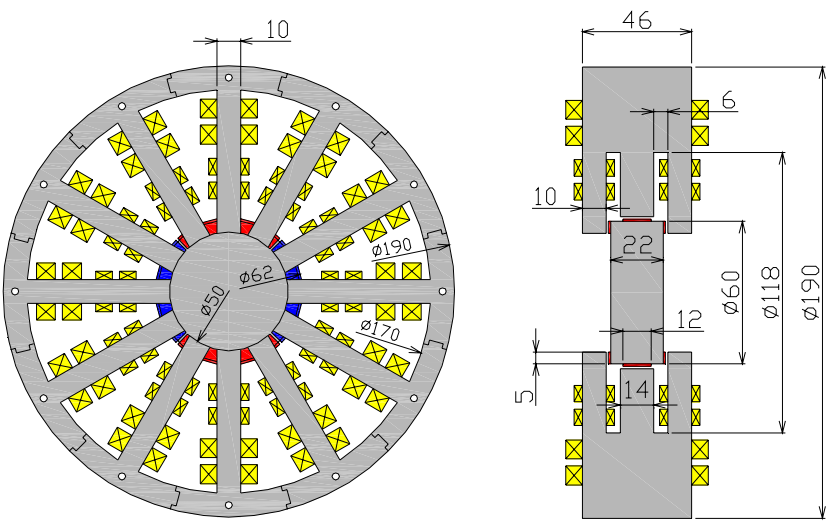

Fig. 3 Dimensions of 5-DOF self-bearing motor

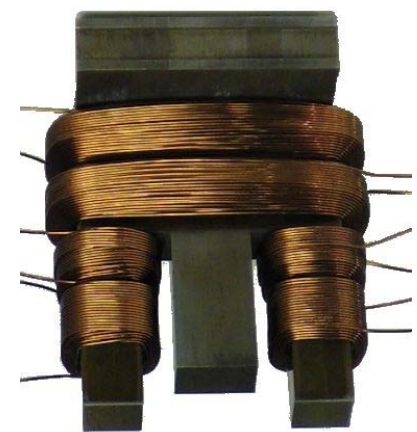

Fig. 4 Photograph of divided stator

Table 1 Design parameters

\begin{tabular}{|c|c|c|}
\hline Parameters & Units & Value \\
\hline Stator Diameter & $\mathrm{mm}$ & 190 \\
\hline Stator Width & $\mathrm{mm}$ & 46 \\
\hline Rotor Diameter & $\mathrm{mm}$ & 60 \\
\hline Rotor Width & $\mathrm{mm}$ & 22 \\
\hline Nominal Air gap & $\mathrm{mm}$ & 1 \\
\hline Thickness of PMs & $\mathrm{mm}$ & 1 \\
\hline Width of Radial PMs & $\mathrm{mm}$ & 12 \\
\hline Width of Axial PMs & $\mathrm{mm}$ & 5 \\
\hline Radial Coil and Motor Coil & Turns & 150 \\
\hline Tilt Coil and Axial Coil & Turns & 100 \\
\hline Supply Voltage & $\mathrm{V}$ & \pm 36 \\
\hline
\end{tabular}




\section{Control Principle}

Figure 5, 6(a), and 7(a) show the control principle of the radial position, axial position, and tilt of the levitated rotor. The pathways of the bias magnetic flux produced by the permanent magnets and the control magnetic flux produced by the electromagnetic coils are shown in the figures. The magnetic flux in one air gap is increased with the control magnetic flux, the flux in the opposite air gap is decreased with it and the force or torque are generated. Figure 6(b) and 7(b) show the control principle with rotation. The rotation of the magnetic fields generated by the excitation coils is synchronized with the rotation of the magnetic fields by the permanent magnets on the rotor.

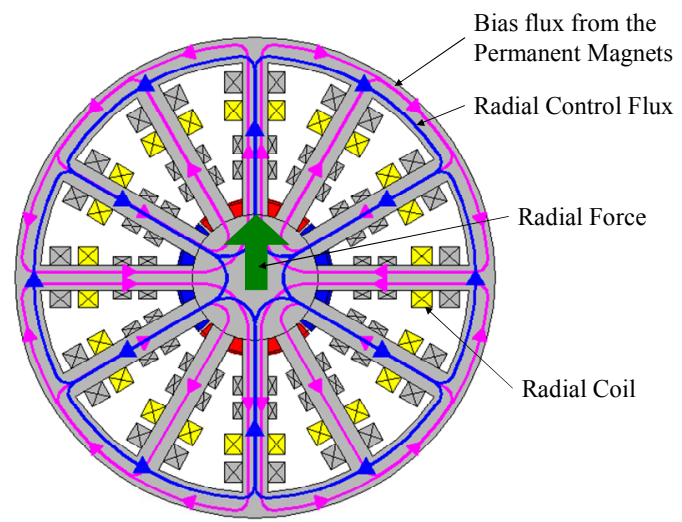

Fig. 5 Principle of radial position control

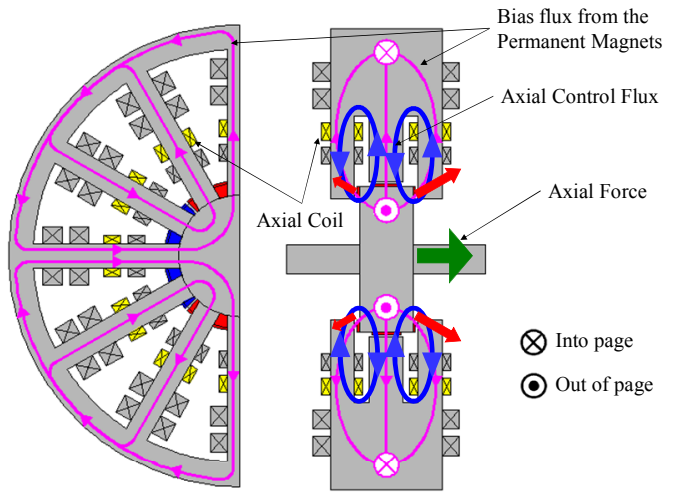

(a) Regulation principle

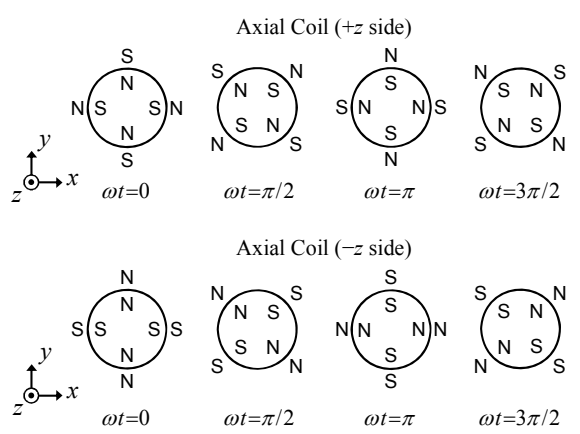

(b) Control with rotation

Fig. 6 Principle of axial position control

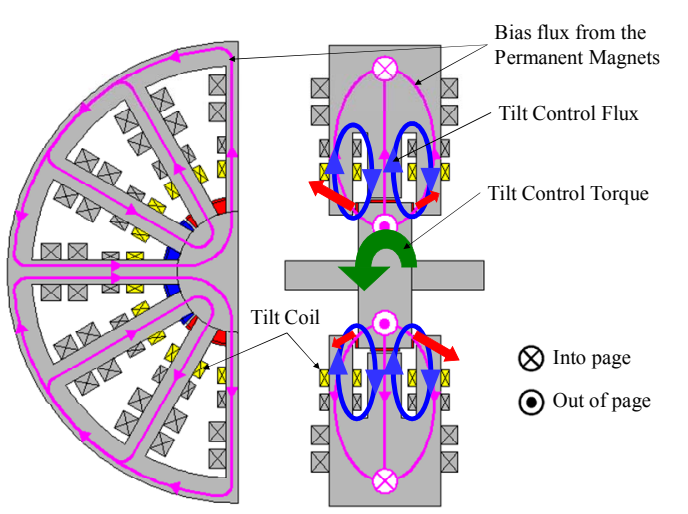

(a) Regulation principle

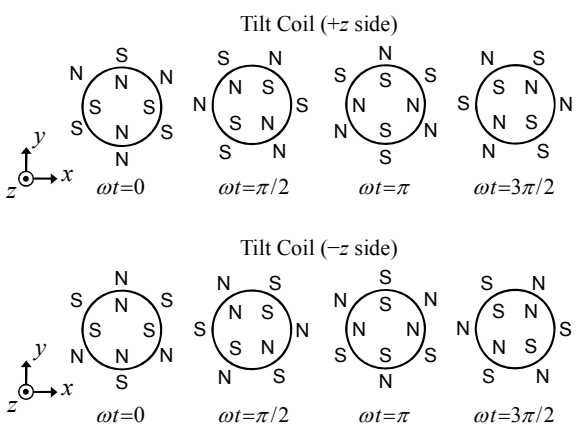

(b) Control with rotation

Fig. 7 Principle of tilt control 


\section{Experiments}

Two experimental setups are built to evaluate the 5-DOF self-bearing motor. One is used to evaluate the radial force and radial position control performance. The other is used to evaluate the tilt control torque and 5-DOF active control performance.

\subsection{Radial position control}

Figure 8 shows a schematic diagram and a photograph of the experimental setup for the radial performance evaluation. The rotor is set on a long shaft. The right end of the rotor shaft is supported by a mechanical ball bearing and the left end of the shaft is magnetically supported by the developed 5-DOF self-bearing motor. Therefore, the rotor can be moved freely in the radial direction and can be rotated. The control performance in the two radial degrees of freedom $(x, y)$ is examined independently with the experimental setup. A touchdown bearing is installed to avoid direct contact between permanent magnets on the rotor and the stator. The radial movable range of the rotor is restricted from $-0.66 \mathrm{~mm}$ to $0.66 \mathrm{~mm}$ from the center position with the touchdown bearing. Two eddy current displacement sensors are used to measure the $x$ and $y$ position of the rotor. A rotary encoder is used to measure the angular position $\theta_{z}$ and the rotational speed of the rotor.

Figure 9 shows the block diagram of the radial position control system. Where $a, b$ are 2-phase 6-pole windings for radial position control and U, V, W are 3-phse 4-pole windings for motor torque. A digital PID controller is implemented on the dSPACE controller board. Where $e(z)$ is error signal, $z$ is shift operator, $\tau$ is sampling time, $K p, K i$, $K d$ are proportional, integral and derivative gain respectively. The control signal $u(z)$ is calculated by the weighted sum of the error signal. Then the control current excites into the electromagnetic coils with the power amplifier. The supply voltages to the power amplifier are plus and minus 36 V's. Rotational speed is also controlled by the digital PID controller. The control parameters for radial position control are summarized in Table 2.

The radial force is measured by changing the current of radial coil while the rotor is fixed at the center position $(y=0 \mathrm{~mm})$. The radial control forces with different radial position $(y=0 \mathrm{~mm}, 0.2 \mathrm{~mm}, 0.4 \mathrm{~mm})$ are also measured. Negative stiffness due to the permanent magnets is measured by changing the rotor position without excitation of the coils $(I=0 \mathrm{~A})$. Impulse response and frequency response of the radial position control with 2-DOF control are measured to evaluate the dynamic radial control performance. The maximum oscillation amplitude of the rotor with rotation is also measured with the 2-DOF control. The impulse response is measured by hammering the rotor while the radial position is controlled at the center position. The frequency response is measured in the frequency sweeping method. Sinusoidal disturbance with amplitude of $0.005 \mathrm{~mm}$ is added to the sensor signal, and the disturbance frequency is varied from $1 \mathrm{~Hz}$ to $400 \mathrm{~Hz}$.

The back electromotive force (EMF) is measured at the terminal of the motor coil when the rotor is driven by an external DC motor. In the experiments of back EMF, both ends of the rotating shaft were supported with mechanical ball bearings.

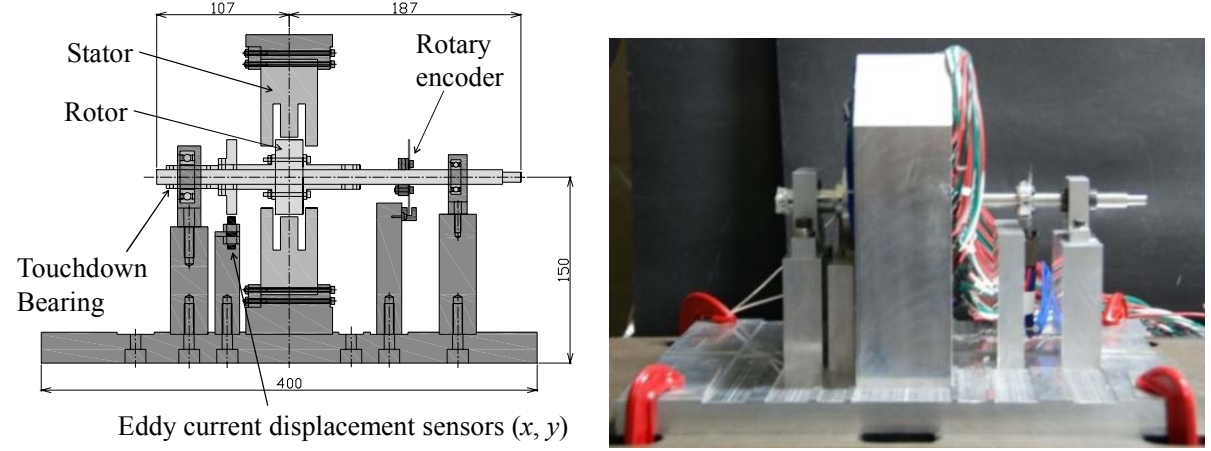

Fig. 8 Schematic diagram and photograph of radial experimental setup 


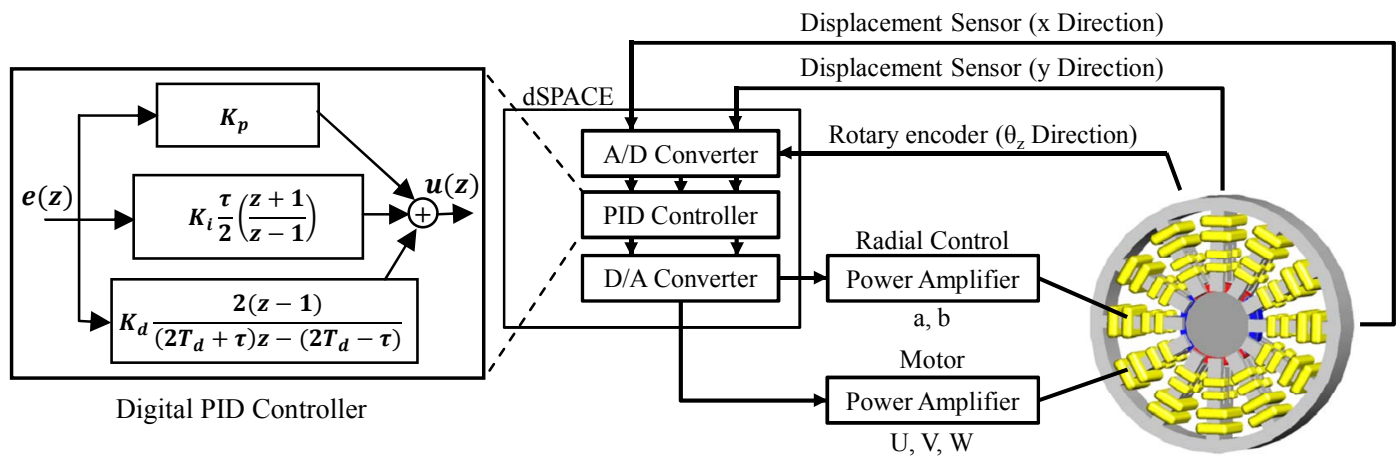

Fig. 9 Block diagram of radial position control system

Table 2 Control parameters for radial position control

\begin{tabular}{|c|c|c|c|}
\hline \multirow{2}{*}{ Parameters } & \multirow{2}{*}{ Units } & \multicolumn{2}{|c|}{ Value } \\
\cline { 3 - 4 } & & $x$ & $y$ \\
\hline Proportional Gain & $\mathrm{V} / \mathrm{mm}$ & 10 & 10 \\
\hline Integral Gain & $\mathrm{V} /(\mathrm{sec} \cdot \mathrm{mm})$ & 8 & 8 \\
\hline Derivative Gain & $\mathrm{V} \cdot \mathrm{sec} / \mathrm{mm}$ & 0.03 & 0.03 \\
\hline
\end{tabular}

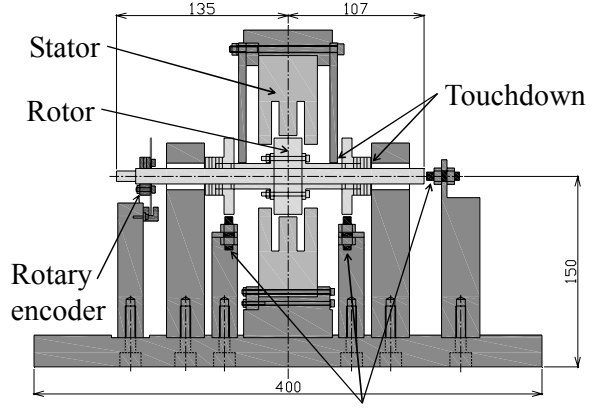

Eddy current displacement sensors

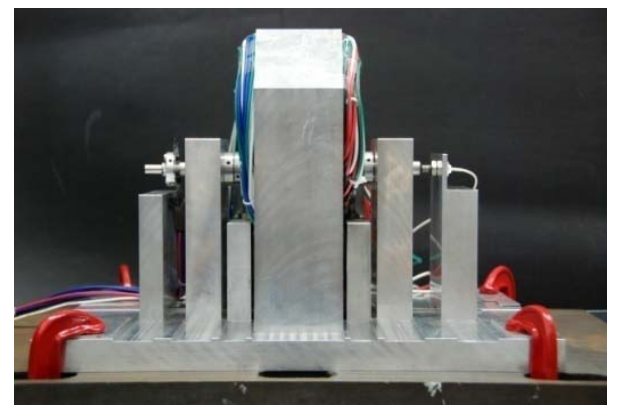

Fig. 10 Schematic diagram and photograph of 5-DOF experimental setup

\subsection{Tilt control and 5-DOF control}

Figure 10 shows a schematic diagram and a photograph of the experimental setup to evaluate the tilt control performance and the 5-DOF active control performance. The rotor with the shaft is supported completely by the 5-DOF self-bearing motor. The radial movable range of the rotor is restricted within $\pm 0.77 \mathrm{~mm}$ with the touchdown. The axial movable range of the rotor is restricted within $\pm 0.58 \mathrm{~mm}$. The maximum tilt angle of the rotor is restricted within $\pm 1.1 \mathrm{deg}$. Five eddy current displacement sensors are used to measure the radial and axial positions of the rotor. Tilt angle is calculated from the sensor signals. A rotary encoder is used to measure the angular position of the rotor $\theta_{z}$ and the rotational speed of the rotor.

Figure 11 shows the block diagram of the control system of the 5-DOF self-bearing motor. The control parameters for 5-DOF self-bearing motor are summarized in Table 3. Control parameters were adjusted manually to obtain the better frequency response with the 5-DOF active control.

Tilt control torque is measured with the 4-DOF active control $\left(x, y, z, \theta_{y}\right)$. The rotor can tilt only in the $\theta_{x}$ direction. Tilt control torque is calculated by measuring the force in the $y$ direction at a position displaced from the center of the rotor in the $z$ direction. 


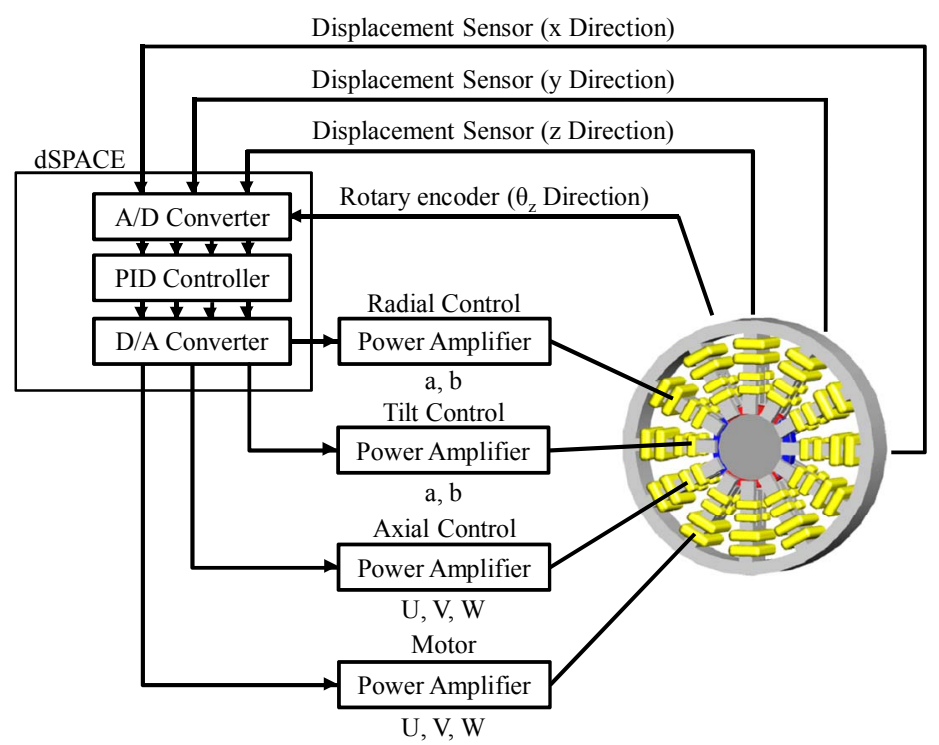

Fig. 11 Control system of 5-DOF self-bearing motor

Table 3 Control parameters for 5-DOF self-bearing motor

\begin{tabular}{|l|c|c|c|}
\hline & Proportional Gain & Integral Gain & Derivative Gain \\
\hline $\begin{array}{l}\text { Radial Position } \\
\text { Control }\end{array}$ & $17[\mathrm{~V} / \mathrm{mm}]$ & $8[\mathrm{~V} /(\mathrm{sec} \cdot \mathrm{mm})]$ & $0.04[\mathrm{~V} \cdot \mathrm{sec} / \mathrm{mm}]$ \\
\hline $\begin{array}{l}\text { Axial Position } \\
\text { Control }\end{array}$ & $35[\mathrm{~V} / \mathrm{mm}]$ & $10[\mathrm{~V} /(\mathrm{sec} \cdot \mathrm{mm})]$ & $0.062[\mathrm{~V} \cdot \mathrm{sec} / \mathrm{mm}]$ \\
\hline Tilt Control & $40[\mathrm{~V} / \mathrm{deg}]$ & $20[\mathrm{~V} /(\mathrm{sec} \cdot \mathrm{deg})]$ & $0.12[\mathrm{~V} \cdot \mathrm{sec} / \mathrm{deg}]$ \\
\hline $\begin{array}{l}\text { Rotational } \\
\text { Speed Control }\end{array}$ & $0.002[\mathrm{~V} / \mathrm{rpm}]$ & $0.005[\mathrm{~V} /(\mathrm{sec} \cdot \mathrm{rpm})]$ & $0[\mathrm{~V} \cdot \mathrm{sec} / \mathrm{rpm}]$ \\
\hline
\end{tabular}

The amplitude of the control current of the tilt angle $\theta_{x}$ is varied from $0 \mathrm{~A}$ to $2 \mathrm{~A}$.

The rotor was successfully levitated with the 5-DOF active control. The frequency responses in the $x, y, z, \theta_{x}, \theta_{y}$ directions were measured with the 5-DOF active control. As in the case of the radial position control, sinusoidal disturbances with amplitude of 0.005 $\mathrm{mm}, 0.02 \mathrm{~mm}$ and $0.03 \mathrm{deg}$ were added to the radial sensor signal, the axial sensor signal, and the tilt angle signal. The disturbance frequency was varied from $1 \mathrm{~Hz}$ to $500 \mathrm{~Hz}$.

\section{Experimental results}

\subsection{Radial position control}

Figure 12 shows the relationship between radial control force and excitation current. The estimated force by the three-dimensional magnetic field numerical analysis using finite element methods is shown for comparison. The rotor position in the radial direction was set at the center in the numerical analysis. The experimental results of the radial force were $49 \%$ of the numerical results. It is considered that the difference between the experimental and numerical results was caused by the assembly error, especially by increase of the reluctance in the divided stator structure. The ratio of radial control force to excitation current for the experimental results was $15 \mathrm{~N} / \mathrm{A}$ and was constant at different rotor positions in the radial direction. The acceleration of the rotor weighed $890 \mathrm{~g}$ was 3.44 $\mathrm{G}$ with the excitation current of $2 \mathrm{~A}$. 


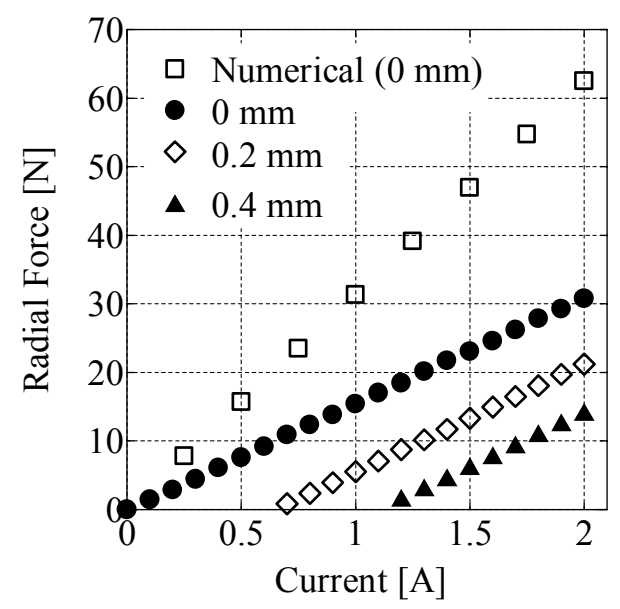

Fig. 12 Relationship between radial force and excitation current with different radial positions $(y=0 \mathrm{~mm}, 0.2 \mathrm{~mm}, 0.4 \mathrm{~mm})$

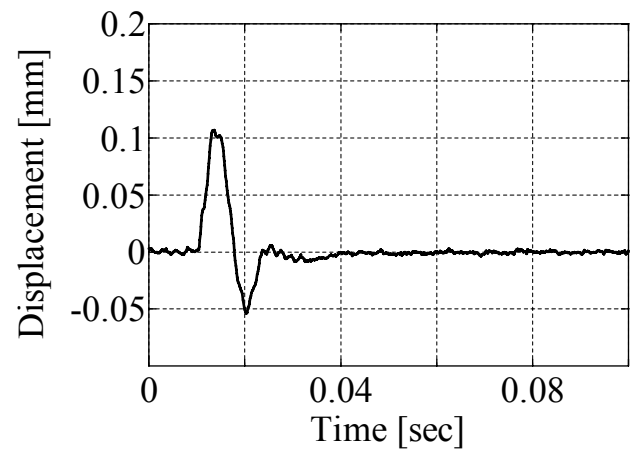

(a) $x$ direction

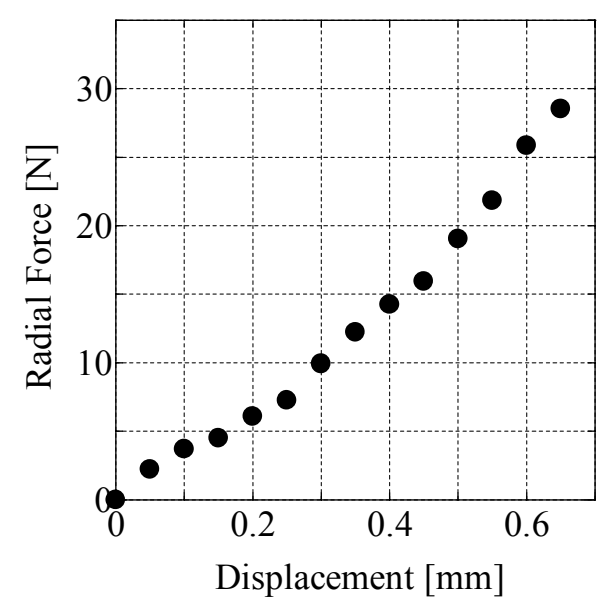

Fig. 13 Radial negative stiffness by permanent magnets $(I=0$ A)

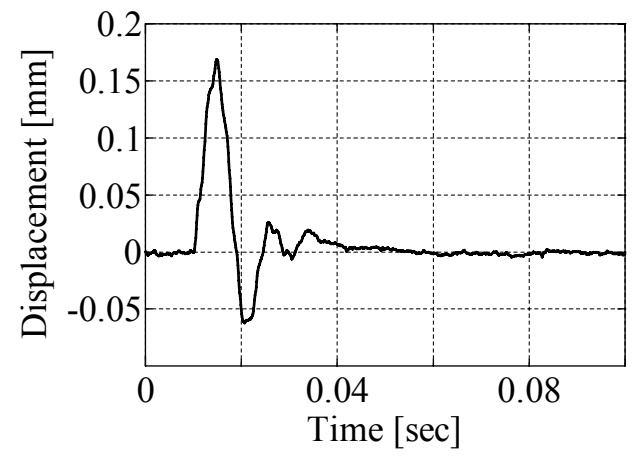

(b) $y$ direction

Fig. 14 Impulse response with 2-DOF control

Figure 13 shows the characteristic of the radial negative stiffness due to the permanent magnets which was measured by changing the rotor position while keeping the excitation current was zero $(I=0$ A). The ratio of force to displacement was about $38 \mathrm{~N} / \mathrm{mm}$. Figure 14 shows the impulse responses in the $x$ and $y$ directions with 2-DOF control. A settling time of $0.03 \mathrm{~s}$ in each direction shows acceptable performance to control the rotor fluctuation at about from 2,000 to 3,000 rpm with amplitude of $0.1 \mathrm{~mm}$. Figure 15 shows the frequency response with 2-DOF control in the $x$ and $y$ directions. Similar results in the $x$ and $y$ directions were obtained. The first resonant peak is observed at $60 \mathrm{~Hz}$ and the amplitude of the resonant peak is sufficiently suppressed, because the damping ratio is considered over 0.5 .

Figure 16 shows the maximum oscillation amplitude of the suspended rotor in the $x$ and $y$ directions with rotation in the condition of 2-DOF control. Similar maximum oscillation amplitudes in the $x$ and $y$ directions was obtained. Figure 17 shows the trajectory of the rotor position with 2-DOF control at rotational speeds of $0 \mathrm{rpm}, 300 \mathrm{rpm}, 500 \mathrm{rpm}$, and 700 $\mathrm{rpm}$. Steady rotation of the rotor at low frequency is observed, while the maximum oscillation amplitude increases as the rotational speed increases. The rotor position in the radial directions were able to control up to a rotational speed of $800 \mathrm{rpm}$. 

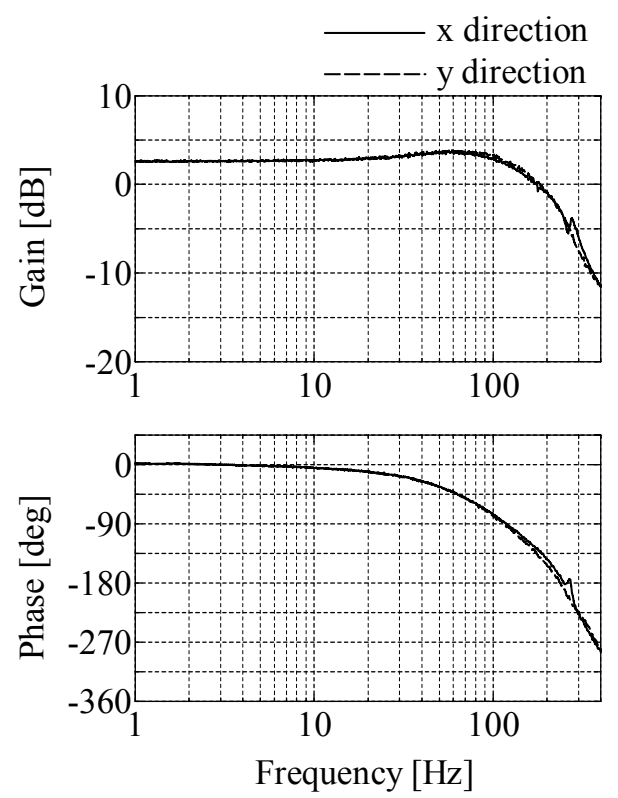

Fig. 15 Frequency response with radial position (2-DOF) control

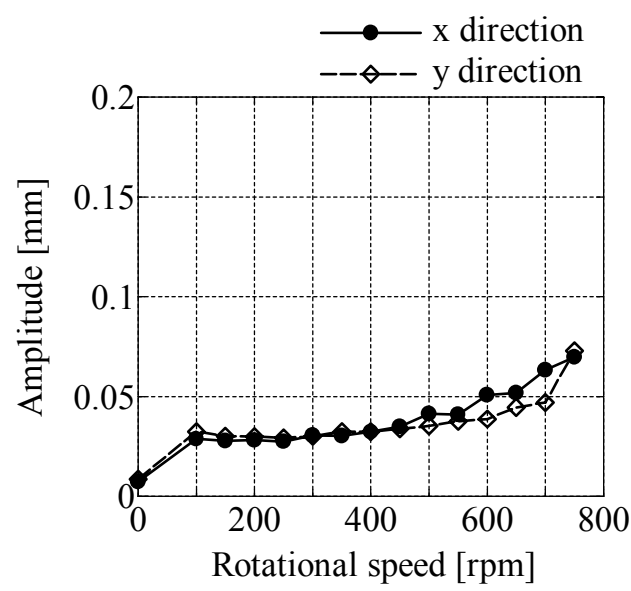

Fig. 16 Maximum oscillation amplitude with radial position (2-DOF) control
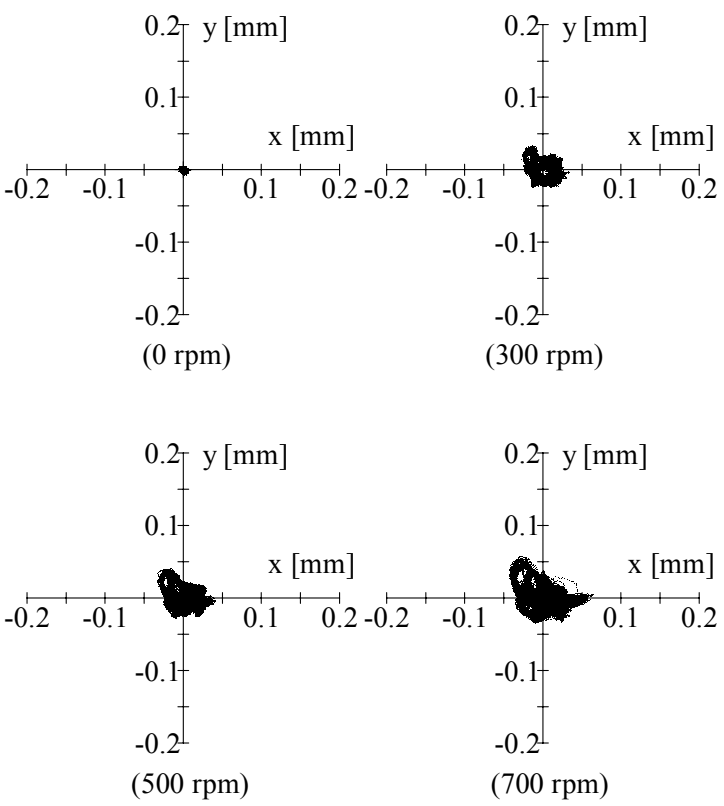

Fig. 17 Trajectory of radial rotor position with 2-DOF control

Figure 18 shows the relationship between the back EMF and the rotational speed. The back EMF increases proportionally to the rotational speed and reaches a supply voltage of $36 \mathrm{~V}$ at a rotational speed of $1200 \mathrm{rpm}$. As the rotational speed increases, the back EMF increases and the control current decreases and the rotor becomes more unstable. This large back EMF is caused by multiple permanent magnets mounted on the rotor.

Figure 19 shows the back EMF waveform at $1200 \mathrm{rpm}$. Due to the tapered edges of the permanent magnets, high harmonic components are decreased and the sinusoidal like waveform is obtained, while the maximum voltage of the back EMF waveform reaches 36 $\mathrm{V}$ at $1200 \mathrm{rpm}$. The back EMF should be decreased by changing the PM configuration to achieve higher speed in rotation. 


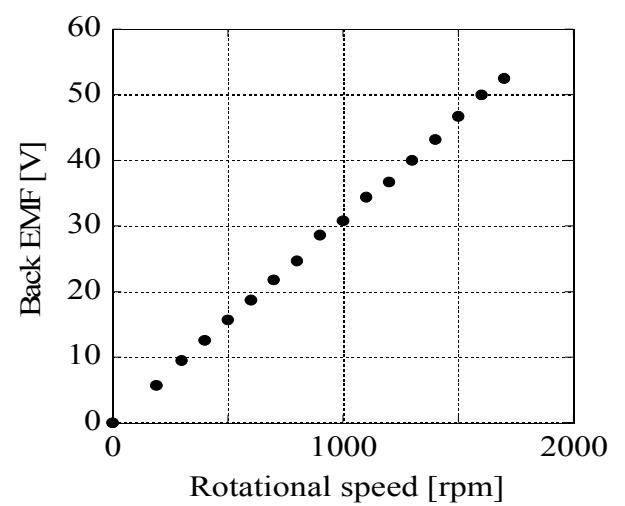

Fig. 18 Back EMF with increased rotational speed

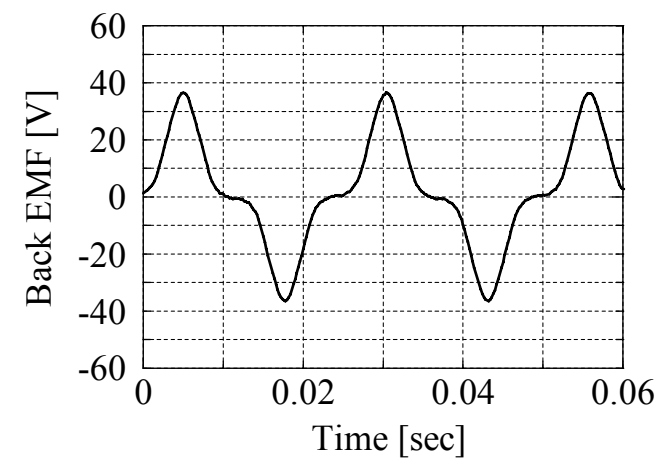

Fig. 19 Back EMF waveform at $1200 \mathrm{rpm}$

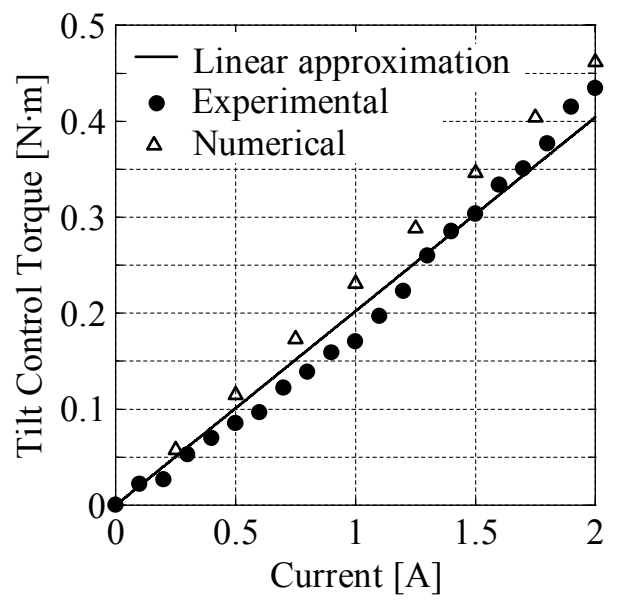

Fig. 20 Tilt control torque

\subsection{Tilt control and 5-DOF control}

Figure 20 shows the relationship between tilt control torque and excitation current. The numerical results are shown for comparison. The ratio of tilt control torque to excitation current for the experimental results, called the torque constant, is $0.2 \mathrm{Nm} / \mathrm{A}$. The experimental results of the tilt control torque are $95 \%$ of the numerical results. The torque to inertia ratio of the rotor is $232 \mathrm{rad} / \mathrm{s}^{2}$.

Figure 21(a) shows the frequency response with 5-DOF control in the $x, y$, and $z$ directions. Similar results in the $x, y$, and $z$ directions were obtained. The first resonant peak in the position control is observed at $100 \mathrm{~Hz}$. The amplitude of the resonant peak in the position control is sufficiently suppressed. Figure 21(b) shows the frequency response with 5-DOF control in the $\theta_{x}$ and $\theta_{y}$ directions. The first resonant peak in the $\theta_{x}$ direction and the $\theta_{y}$ direction are observed at $50 \mathrm{~Hz}$ and $70 \mathrm{~Hz}$, respectively. The frequency bandwidth of tilt control is lower than that of the position control. The frequency bandwidth in the $\theta_{x}$ direction is particularly low because of gravity, but is sufficient to control the rotor up to a rotational speed of $3000 \mathrm{rpm}$. The amplitude of the resonant peak of the tilt control is sufficiently suppressed for the sinusoidal disturbance with amplitude of $0.03 \mathrm{deg}$. 

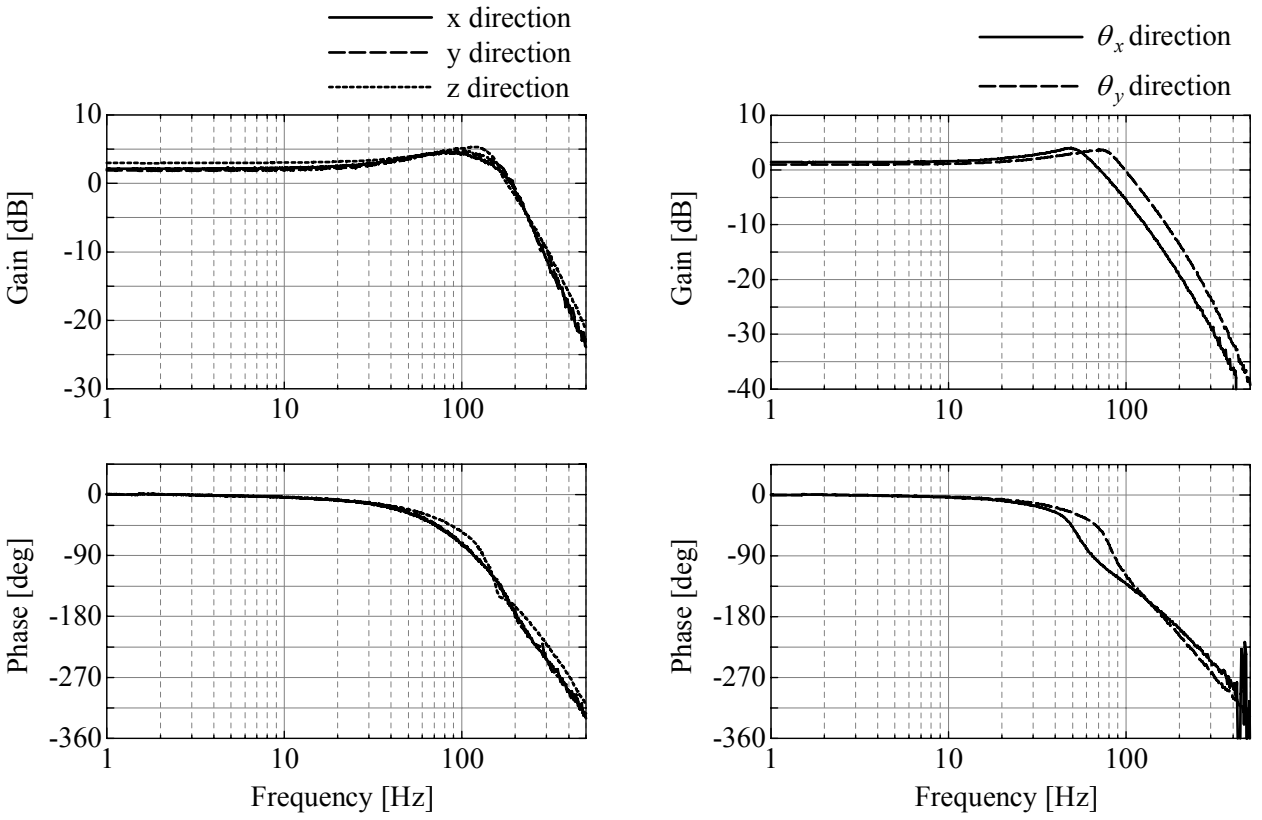

(a) Radial and axial position control

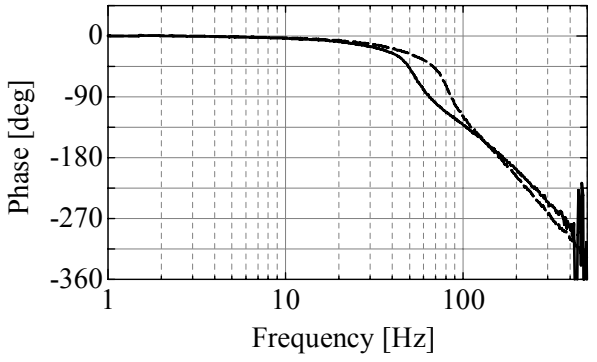

(b) Tilt control

Fig. 21 Frequency response with 5-DOF control

\section{Conclusions}

A novel 5-DOF actively controlled self-bearing motor which combines the functions of a motor, two radial AMBs, and an axial AMB has been developed to achieve smaller size and higher performance. The prototype 5-DOF self-bearing motor generated sufficient radial force of $15 \mathrm{~N} / \mathrm{A}$ to overcome the radial negative stiffness of $38 \mathrm{~N} / \mathrm{mm}$ and sufficient tilt control torque of $0.2 \mathrm{Nm} / \mathrm{A}$ to stabilize the rotor. The sufficient frequency bandwidth was observed in the frequency response and the self-bearing motor successfully suppressed vibration at the resonant frequencies.

\section{References}

(1) Okada, Y., Dejima, K., and Ohishi, T., "Analysis and Comparison of Synchronous Motor and Induction Motor Type Magnetic Bearing," IEEE Transaction on Industry Applications, vol. 31, no. 5, pp.1047-1053, 1995.

(2) Matsuda, K., Kita, T., Okada, Y., Masuzawa, T., Oishi, T., Taenaka, Y., Yamane, T., "Radial-type Self-bearing Motor for Nonpulsatile-type Artificial Heart", JSME International Journal, Series C, vol.43, no.4, pp. 941-948, 2000.

(3) Onuma, H., Masuzawa, T., Matsuda, K, and Okada, Y., "Magnetically Levitated Centrifugal Blood Pump with Radially Suspended Self-bearing Motor", Proc. Ofthe 8th Int. Symp. on Magnetic Bearings, Mito, Japan,Aug. 26-28, 2002.

(4) Matsuda, K., Ishikawa, T., Masuzawa, T., Kondo, R., "Development of Small and High-Performance Self-Sensing Motor for Nonpulsatile-Type Artificial Heart", CD-ROM Proc. of Dynamics and Design Conference, 2007. (Japanese).

(5) Matsuda, K., Ishikawa, T., Masuzawa, T., Kondo, R., "Development of the 5-Axis Active Control Type Self-Bearing Motor”, Proc. of 16th MAGDA Conference, pp.147-152, 2007. (Japanese).

(6) Matsuda, K., Ishikawa, T., Masuzawa, T., Kondo, R., "Levitation and Rotation Characteristics of the Five-axis Actively Controlled Self-Bearing Motor", Proc. of 20th Symposium on Electromagnetics and Dynamics, pp.619-622, 2008. (Japanese). 